\title{
Organization of geomechanical monitoring for non-metallic deposits chambers roofs
}

\author{
Serhii Skipochka ${ }^{1,}{ }^{*}$, Viktor Serhiienko ${ }^{1}$, Volodymyr Amelin ${ }^{1}$, and Oleh Sytnichenko ${ }^{2}$ \\ ${ }^{1}$ Institute of Geotechnical Mechanics named by N. Poljakov of National Academy of Sciences of \\ Ukraine, 49005, Dnipro, Simferopolska Str., 2a, Ukraine \\ ${ }^{2}$ Additional Liability Company «Siniat», 84500, Bakhmut, Lomonosov Str., 3, Ukraine
}

\begin{abstract}
The purpose of the work is the development and implementation of methods and monitoring equipment and diagnostics of the mine workings roof state of non-metallic deposits for providing of long safety operation of large section chambers. The task was solved by the organization and performance of geomechanical monitoring of working roofs state. Experience of a three-level system monitoring creation on the gypsum deposit in the city Bakhmut (Ukraine) is described. Monitoring included visual inspection, filing of roof deformations and vibroacoustic diagnostics. Examples of the long overseeing results by dangerous sites of the working roof are given.
\end{abstract}

\section{Introduction}

Considerable part of nonmetallic construction raw materials in the world are mined underground. Mostly use chamber-and-pillar system of development. Parameters of chambers of some deposits are specified in Table 1.

Table 1. Chambers parameters of some building materials deposits.

\begin{tabular}{|l|l|l|c|c|c|}
\hline Country & Raw materials & \multicolumn{1}{c|}{ Deposit } & Depth, $\mathrm{m}$ & Height, $\mathrm{m}$ & Width, $\mathrm{m}$ \\
\hline \multirow{3}{*}{ Ukraine } & gypsum & Artemivske & $70-100$ & $15-18$ & $8-11$ \\
\cline { 2 - 6 } & \multirow{2}{*}{ limestone } & Novo-Odesske & $20-30$ & 5.2 & $6-8$ \\
\cline { 3 - 6 } & & Inkermanske & $20-30$ & 13 & $8-12$ \\
\hline \multirow{3}{*}{ Russia } & gypsum & Novomoskovskoye & $110-130$ & $9-11$ & $10-11$ \\
\cline { 2 - 6 } & anhydride & Gorosubovskoye & $130-150$ & $9-14$ & 8 \\
\cline { 2 - 6 } & marble & Kibik-Kordonskoye & $150-200$ & $12-18$ & $8-12$ \\
\hline \multirow{2}{*}{ Moldova } & \multirow{2}{*}{ limestone } & Grigoriopol & $40-70$ & 5.2 & $5-9$ \\
\cline { 3 - 6 } & & Chisineu & $70-100$ & 2.6 & 8 \\
\hline \multirow{2}{*}{ Italy } & \multirow{2}{*}{ marble } & Carrara & $20-30$ & $8-10$ & $4-6$ \\
\cline { 3 - 6 } & & Candoglia & $30-50$ & $18-22$ & $8-10$ \\
\hline Portugal & marble & Alentejo & $65-90$ & $10-14$ & 9 \\
\hline
\end{tabular}

\footnotetext{
*Corresponding author: skipochka@ukr.net
} 
By the sizes, chambers belong to developments of big section. It imposes increased requirements to control of a condition of a roof of workings, especially taking into account the insignificant depth of fields and existence on a surface of objects of civil, industrial and agrarian function. The market value of the extracted mineral raw materials is small. Service life of chambers is decades. Fastening of a roof of chambers is incidental. Natural geomechanical processes in rock mass promote gradual decrease in stability of a roof of chambers. In the absence of control, the caving of a roof is possible. Large accidents in gypsum mines in Nikitovka (Ukraine), Shante-Lu (France) and Koshava (Bulgaria) are known. In zones of geological faults mining operations provoked inrushes in a roof and on the gypsum field in Bakhmut (Ukraine). As a result of it on the land surface pits were formed (Figure 1).

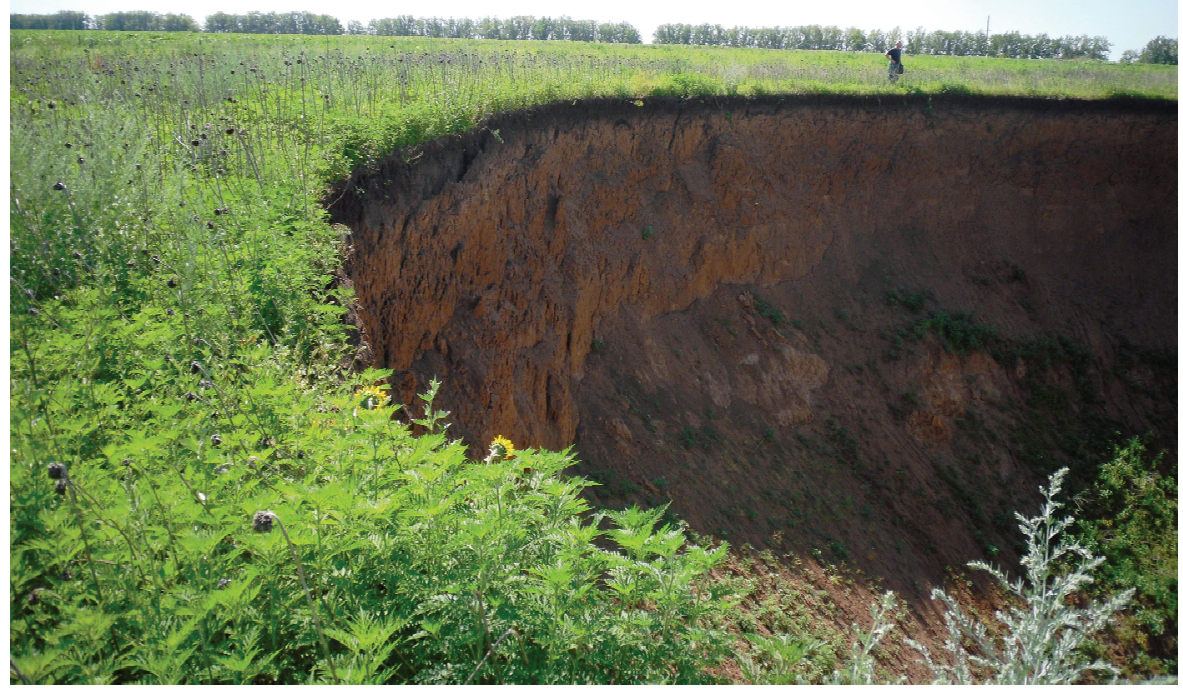

Fig. 1. The pit over gypsum mine workings in Bakhmut (Ukraine).

Emergence of contingency situations in mines is promoted by the following factors: the long life of workings, increase in total length of constantly used workings, complication of mining and geological conditions. Necessary condition of safety of work of mines and surrounding medium is the organization of geomechanical monitoring of a condition of a roof of workings. Further the developed structure of monitoring for the gypsum mine of ALC "Siniat" (Bakhmut, Ukraine) of the international concern "Etex Group" is given. At the enterprise, the European requirements to the culture of production and safety of work of miners successfully are implemented.

The long joint creative commonwealth of specialists of the ALC "Siniat" and scientists of Institute of geotechnical mechanics of National Academy of Sciences of Ukraine allows in difficult mining and geological conditions to conduct profitable operation of the deposit. Creation of a complex system of observations of a condition of workings became one of successfully implemented projects of cooperation. Its major element is control of a roof. It is carried out in common by specialists of the enterprise and institute. When organizing the control, the results of monitoring at gypsum deposits of Russia (Kamsko-Ustinskoye, Peshelanskoye and Novomoskovskoye) [1] were taken into account. The best methodological and instrumental developments of other organizations are taken into account [2-7].

Preferable use of one of methods was the first flaw of the schemes of control used earlier. The prevailing place was taken by visual inspection. Other methods were used fragmentary and did not make a whole system. 
The second flaw consisted in definition of a condition of a roof only by results of the current diagnostics. The executed researches showed that dynamics of development of deformation processes in a roof is crucial. At some point, the quantitative accumulation of defects in rock mass passes into qualitative. Sign of a dangerous state is not the absolute value of parameter, but its jump. Therefore the following requirements were imposed to monitoring: to provide operational control of the situation on the concrete site of the mine field; to provide a possibility of realization of organizational and technical solutions which exclude emergency or reduce damage from influence of ineradicable natural factors; not to contradict requirements of national normative documents in the sphere of labor protection; to be technically and economically coordinated with opportunities of production structure of the enterprise

\section{Methods}

The developed technique takes into consideration the main mining, geological and technological situations at operation of developments and has flexible structure. Taking into account the extensive nomenclature and continuous modernization of technical means their concrete types were not discussed.

By the complexity level three levels of geomechanical monitoring are provided: low, carried out on the sites by the master, the mine master, the head of the site according to requirements of safety rules [8]; medium, carried out by service of overseeing by excavations, including documenting of results of observation and roughing-out of data array; high, carried out by one or several specialized organizations with a necessary hardware on separate, particularly complex, sites of the mine field.

Time frames of realization of monitoring provide operating, current, long-term and specialized types of monitoring of a condition of a roof of underground chambers. Features of their realization for different levels of monitoring in Table 2 are displayed.

Table 2. Application conditions of different monitoring forms.

\begin{tabular}{|l|c|c|c|}
\hline \multirow{2}{*}{ Type of monitoring } & \multicolumn{3}{c|}{ Monitoring level } \\
\cline { 2 - 4 } & low & medium & high \\
\hline Operating & in shifts & if necessary & - \\
\hline Current & everyday & on the approved schedule & - \\
\hline Long-term & - & on the approved schedule & continuously \\
\hline Specialized & - & - & disposable \\
\hline
\end{tabular}

For different levels of monitoring a particular set of the used control methods is provided (Table 3 ).

Table 3. Roof control methods for different levels of monitoring.

\begin{tabular}{|l|l|l|}
\hline \multirow{2}{*}{$\begin{array}{c}\text { Monitoring } \\
\text { level }\end{array}$} & \multicolumn{2}{|c|}{ Testing methods } \\
\cline { 2 - 4 } & \multicolumn{1}{|c|}{ Basic } & \multicolumn{1}{|c|}{ additional } \\
\hline Low & Visual inspection from floor of chambers & \multicolumn{1}{|c|}{ - } \\
\hline \multirow{3}{*}{ Medium } & $\begin{array}{l}\text { geometrical parameters of the revealed defects, } \\
\text { installation of beacons on cracks and monitoring of } \\
\text { their state, registration of the stationary tools state, } \\
\text { High }\end{array}$ & $\begin{array}{l}\text { Drilling } \\
\text { control holes for } \\
\text { determination of } \\
\text { thickness of } \\
\text { layers }\end{array}$ \\
\hline & $\begin{array}{l}\text { Creation of electronic archive of photos of the most } \\
\text { problem sites, vibroacoustic diagnostics, installation of } \\
\text { means of constant control and their technical inspection }\end{array}$ & $\begin{array}{l}\text { Selection and } \\
\text { test of a core in } \\
\text { vitro }\end{array}$ \\
\hline
\end{tabular}


According to requirements "Safety rules ..." [8] monitoring of the lowest level is carried out in shifts by the head of change before works and daily the supervising foreman. Visual inspection without use of lifting tools allows revealing only the most significant changes of a geomechanical situation. Filing of results of inspection at this level has descriptive character. Monitoring of the average level provides detailed visual inspection of a roof with use of the telescopic elevator. At the same time fix the revealed defects and their geometrical parameters measure (Table 4).

Table 4. Visually recorded defects of a roof.

\begin{tabular}{|l|l|l|}
\hline \multicolumn{1}{|c|}{ Type of defect } & \multicolumn{2}{c|}{ Qharacteristics (signs) } \\
\cline { 2 - 3 } Crack & $\begin{array}{l}\text { length, disclosure, shift of } \\
\text { boards }\end{array}$ & $\begin{array}{l}\text { "Healing" or } \\
\text { development }\end{array}$ \\
\hline $\begin{array}{l}\text { The rock slab separating } \\
\text { from the massif }\end{array}$ & geometrical dimensions & $\begin{array}{l}\text { Stability in case of } \\
\text { induce cavind }\end{array}$ \\
\hline $\begin{array}{l}\text { Replacement of a } \\
\text { protective gypsum pack } \\
\text { with soft rocks }\end{array}$ & Area & $\begin{array}{l}\text { Geological description of } \\
\text { the replacing rocks }\end{array}$ \\
\hline Site of moistening & Area & $\begin{array}{l}\text { Characteristic of extent } \\
\text { of moistening }\end{array}$ \\
\hline $\begin{array}{l}\text { Damage of the "anchor } \\
\text { with a grid" system }\end{array}$ & area of maintaining & $\begin{array}{l}\text { Specification of defect: } \\
\text { destruction, corrosion, } \\
\text { etc. }\end{array}$ \\
\hline
\end{tabular}

Within monitoring of the medium level establish beacons for control of dynamics of disclosure of cracks. For short-term observations use plaster, cement and glass beacons. Their task consists in identification of the fact of increase in disclosure of a crack. For the long overseeing by dynamics of disclosure use bladed beacons. Their design and the scheme of installation are presented in Figure 2.

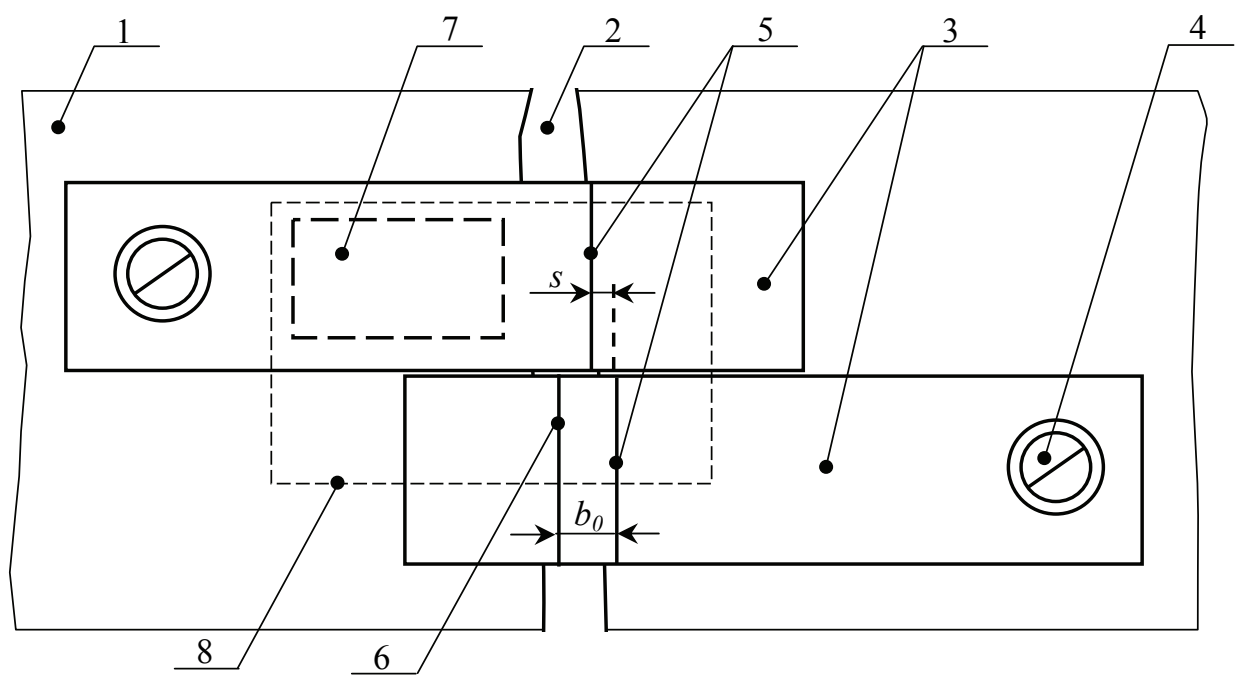

Fig. 2. Construction of the bladed beacon: 1 - roof, 2 - fracture, 4 - plate, 4 - rock bolt, 5 - sighting line, 6 - basic line, 7 - place for designation of beacon number, 8 - frame boundary when shooting.

The sighting line 5 is drawn immediately after installation of the beacon in the form of a piece of the straight line passing through both plates. Basic line 6 is put on one of plates at 
in advance defined distance $b_{0}$. Process of monitoring consists in periodic photography of the beacon with high-res (not lower than 12 Megapixel). Segments of the hairline line on both plates, a part of the basic line and number of the beacon shall get into the shot. Also the installation mode is provided in a shot of date of photography. In case of computer processing of a picture with big increase define $s / b_{0}$ relation. Then on the known value of $b_{0}$ calculate real value of extension of $s$ of a fracture from the moment of installation of the beacon. Resolution capability of monitoring in case of qualitatively the executed photos of the beacon makes order $0.2-0.3 \mathrm{~mm}$. Accumulating electronic archive of photos, it is possible to keep track of dynamics of development of a fracture for a long time.

For execution of preventive engineering actions for support of maintenance of a roof in secure state it is necessary to know its building.

One of tasks of monitoring of the medium level is execution of control drilling. Determine thickness of layers in a roof by its results and its geological structure. In case of high level monitoring execution, the most problem sections are exposed to visual survey are photographed. The periodicity of photography accepted by default - once a quarter. In case of explicit progressing of deformation processes the temporal period between executions of monitoring is reduced. Place a measured tape for determination of the extent of defect in a frame. The example of the exfoliating rock slab in a roof of workings given in the Figure 3.

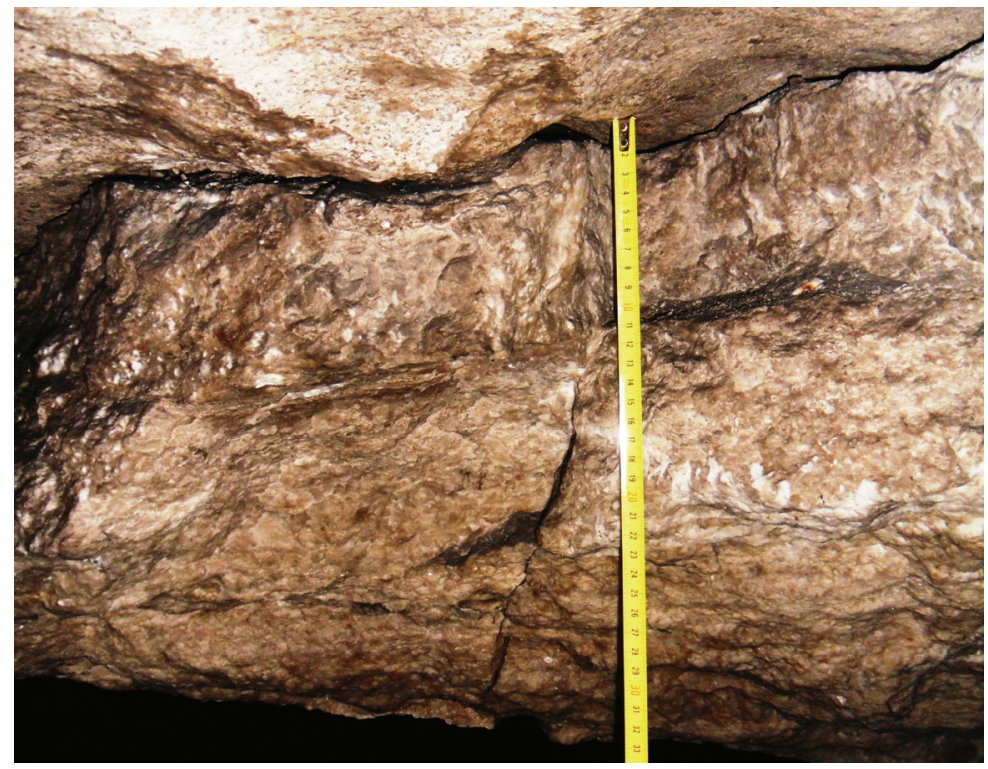

Fig. 3. A photo of separation in a roof of the main transport gallery.

In case of computer processing of the picture the necessary linear extent of defect is determined. The analysis of electronic archive of photos for long time allows keeping track of dynamics of development of deformation processes in a ceiling of roof.

Vibroacoustic diagnostics allows revealing the latent defects on a section of rock mass in parameters of damped oscillations [9]. Excitation of oscillations is realized single shock. Diagnostics of a roof includes: primary continuous monitoring of a roof for identification of an incipient state of process of stratification in a protective pack which is not revealed in the visual path; repeated periodic monitoring of earlier revealed sites of stratification; assessment of stability of the revealed visually unstable blocks; assessment of stability of the pedigree blocks delineated by cracks on a roof surface.

The equipment description and operation instructions are provided in $[10,11]$. Diagnostics of a roof is carried out from the telescopic elevator. The operator installs the 
contact receiver of vibration on a roof and about $1 \mathrm{~m}$ strikes blow in a controlled point apart. The equipment keeps result of monitoring on the given time slice. Process of monitoring is illustrated by Figure 4 .

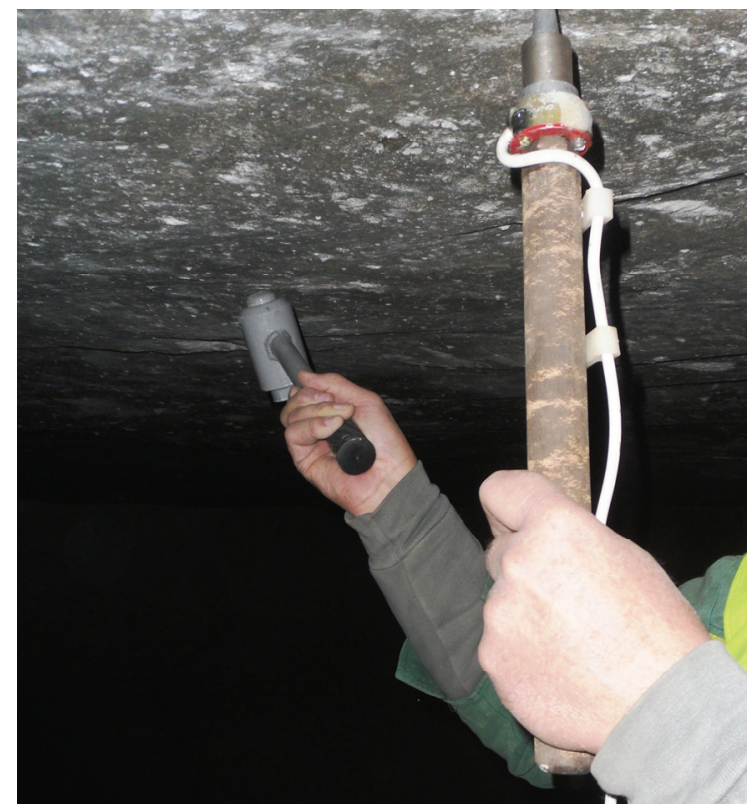

Fig. 4. Realization of vibroacoustic diagnostics of a roof of development by basic option.

Because of the uncomfortable working position it is difficult for operator to strike at the same time the most powerful blow and to provide stable contact of the receiver with the massif. Therefore in basic option of monitoring the best results on informational content are yielded by parameter - a relaxation time of oscillatory process which does not depend at impact force. Despite limited base of monitoring and influence of a ghost mechanical pulse on the receiver through a cabin design after striking this scheme is used as the main. The scheme of vibroacoustic monitoring with big base is developed and approved. In this case the receiver has permanently in the place, comfortable for the recording equipment, and carry out exaltation of a roof step by step from a cabin of the telescopic elevator. When using such scheme oscillatory process of the site of a roof as the thick plate jammed on a contour it is almost localized in the neighborhood of a impact point. Other site of rock mass between the activator and the receiver serves as an acoustic wave guide. The scheme is illustrated by Figure 5 .

The scheme at realization of conditions is implemented: high and stable impact energy; high sensitivity of vibration receiver and its stable contact with a roof; low level of acoustic noise; the base of monitoring is much more sizes of the surveyed site.

High sensitivity of receiver and stable acoustic contact are provided with its fastening to the massif quick-hardening mix. Feature of distribution of a wave packet to the vibration receiver - natural frequency filtration of a signal. The low-frequency portion of a spectrum containing the resonances, characteristic of defects, fades less in comparison with highfrequency. On low frequencies when excitation defects the substantial increase of a vibration amplitude is registered. At stabilization of impact parameters change of level of a signal can exceed much the variations caused by instability of conditions of excitation of oscillations and also change of base of monitoring. From one installation of the receiver control up to 30 points. 
For monitoring of a roof of the long workings with small roadway cross-section is used the scheme provided on Figure 6.

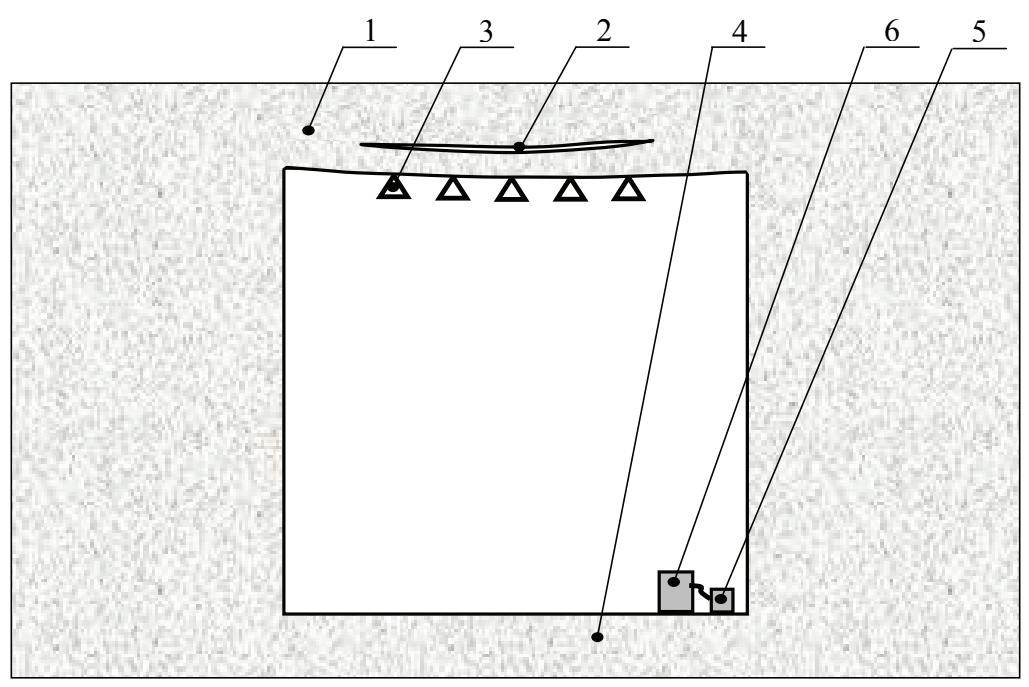

Fig. 5. The scheme of vibroacoustic diagnostics of a roof on big base of monitoring: 1 - ceiling of chambers, 2 - stratification, 3 - shock point, 4 - floor of chambers, 5 - vibration receiver, 6 recording equipment.

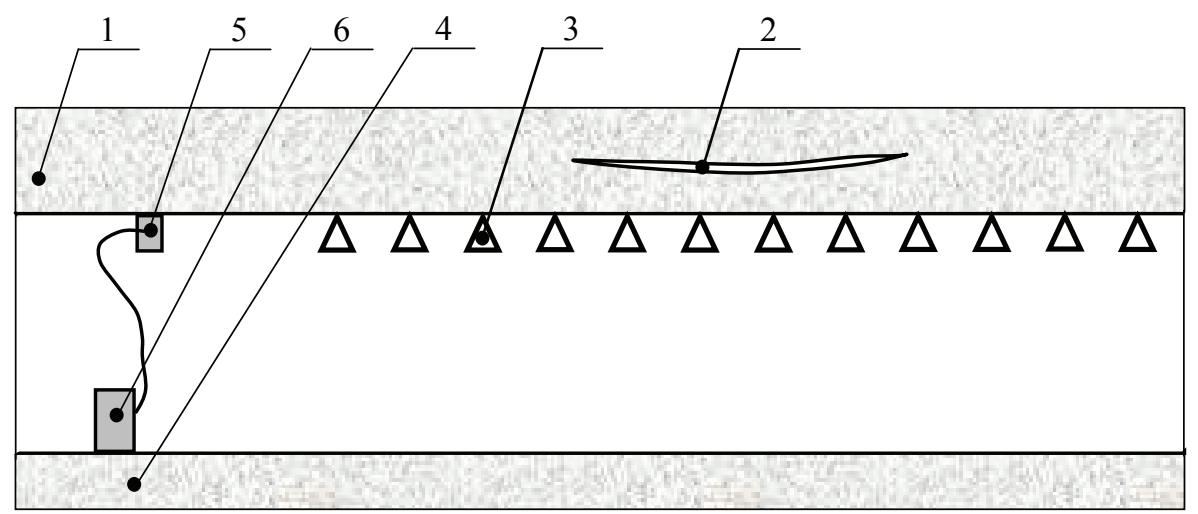

Fig. 6. The scheme of vibroacoustic diagnostics of a roof in development working: 1 - ceiling of chambers, 2 - stratification, 3 - shock point, 4 - floor of chambers, 5 - vibration receiver, 6 recording equipment.

When using such scheme for identification of the abnormal sites beforehand the established criteria values are not necessary. Their selection along a profile happens by comparison of values in more remote points in comparison with more close ones. In the absence of defects in a roof the initial vibration amplitude in a low-frequency portion of a spectrum monotonically decreases in process of removal of the receiver from an exaltation point. Sign of stratification is significant increase in amplitude, despite the increasing base of monitoring. The specified regularity is illustrated by Figure 7. Deformations of an immediate roof of the gypsum mine are very insignificant. The critical deflection of a protective pack is estimated of $10-20 \mathrm{~mm}$. The modern laser registrars of deformations with a high precision provide measurements in the specified range [12]. However, their use demands of additional attracting of the specialized organization. 
Optimal solution - use of the indicator stations set on deep bench mark. The station provides the measurement range of vertical deformation to $10 \mathrm{~mm}$ with resolution capability of $0.01 \mathrm{~mm}$. With annual execution the service life of the station makes up to 10 years. On sections of the explicit movement of blocks the most reliable and convenient in operation were developed multistage signaling devices with the dropping-out signal elements.

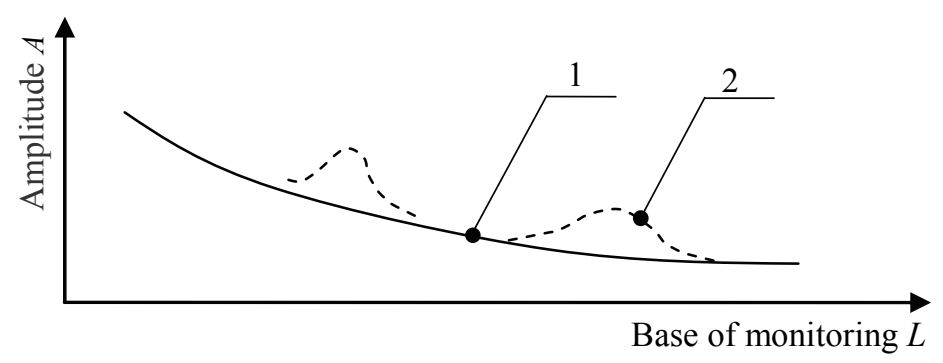

Fig. 7. Dependence of a vibration amplitude on base of monitoring for a roof of development working with existence and lack of stratifications: 1 - lack of stratifications in a roof, 2 - sign of stratification.

The quantity of steps of operation is from 3 to 6 depending on design version. Every of steps is configured individually on operation at a certain deformation in the range about 1 up to $20 \mathrm{~mm}$. Resolution capability of a threshold of operation makes $0.5 \mathrm{~mm}$. Service life of signaling devices without test - not less than 10 years. The appearance of the signaling device of vertical deformations of a roof intended for installation on a deep bench mark is presented in Figure 8.

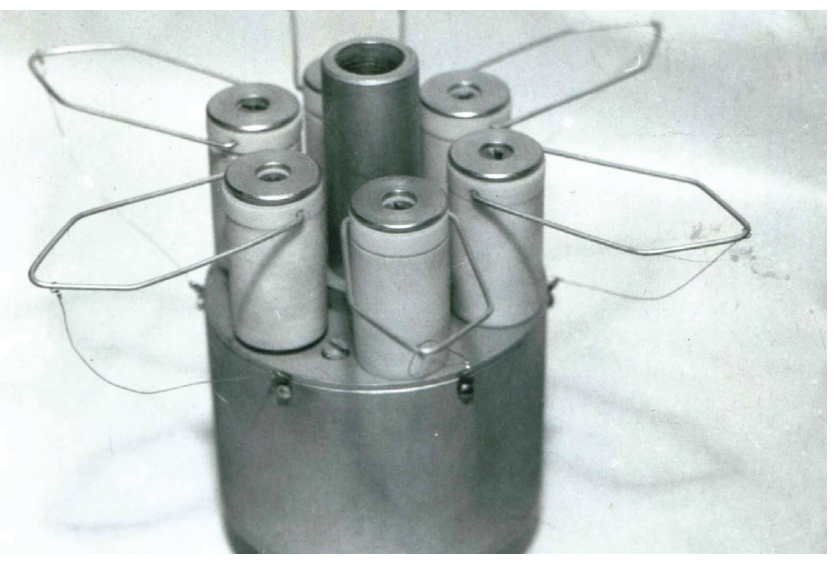

Fig. 8. Appearance of a six-step signaling device of roof deformations.

In zones of carsts the significant change of properties of rocks is observed. For adjustment of the dimensions of chambers and pillars also the complex of characteristics of rocks is necessary for calculation of chart of supports. For this purpose the third level of monitoring provides sample drawing and their laboratories tests in institute. Definition to 12 characteristics is possible.

\section{Results and discussion}

The total duration of overseeing the gypsum mine workings with participation of institute is over 40 years. During the specified time there were irreversible geomechanical processes in the mine roof. They considerably reduced stability. The adjusted system of observations 
and timely performance of engineering preventive actions allowed to prevent the emergency development of situations and to save mine. The typical phenomenon in a roof of working, is gradual formation of block structure with threat of the subsequent caving. Long overseeing of indicator stations by network allowed revealing the main regularities of deformations in a roof of working (Table 5).

Table 5. Deformations development dynamic in a gypsum mine working roof.

\begin{tabular}{|c|l|c|c|}
\hline Stage & \multicolumn{1}{|c|}{ Process } & $\begin{array}{c}\text { Duration, } \\
\text { years }\end{array}$ & $\begin{array}{c}\text { Speed of deformation, } \\
\text { mm/year }\end{array}$ \\
\hline 1 & Stratification of rocks of a roof & to 10 & to 0.3 \\
\hline 2 & Formation of a single large fracture & $2-5$ & $0.3-0.5$ \\
\hline 3 & Formation of large-block structure & $1-3$ & $0.5-1.0$ \\
\hline 4 & Formation of shallow blocks & to 1 & more than 1 \\
\hline
\end{tabular}

Dynamics of development of fractures and zone of stratification in a roof by results of vibroacoustic monitoring is illustrated on the example of chamber \# 31 of the VII stall (Fig. 9).

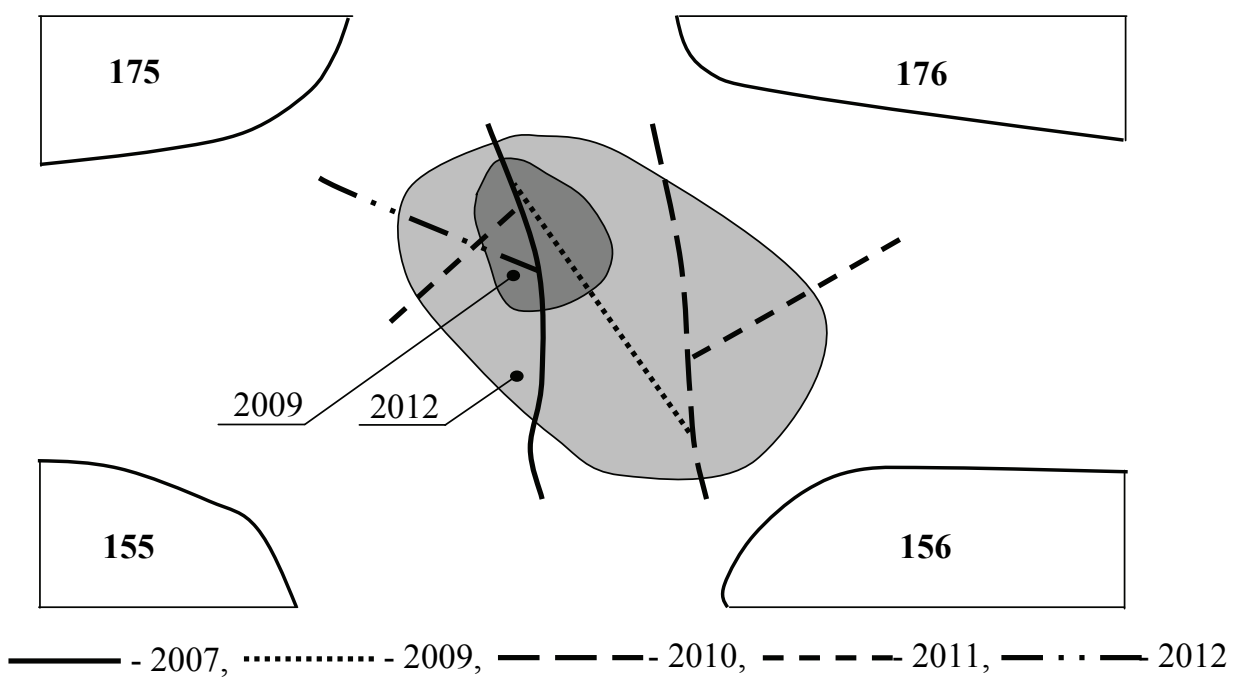

Fig. 9. Development by years of a system of fractures and increase of area of stratification in a ceiling of chamber.

The chamber was fulfilled in 1992 and within more than 10 years its visual inspection did not show signs of violation of a roof. The first longitudinal fracture in a roof appeared in 2007, following - in 2009. The first signs of stratification in a roof received with use of a vibroacoustic method were also found in 2009. Development of block structure in a roof of working happened 4 years. Periodic measurements of disclosure of an initial longitudinal fracture were shown by its increase for the specified period from 5 to $10 \mathrm{~mm}$. Disclosure of other fractures by 2012 made from 1 to $3 \mathrm{~mm}$.

Regularly carried out vibroacoustic diagnostics showed the considerable expansion of a zone of stratification in a roof. Due to potential danger of further operation, working was closed access for people and machines. In two years there was a working roof caving.

In some cases deformation processes in a protective pack of a roof of workings don't fade and don't lead to emergence of new fractures. An example is the site of transport gallery between pillar \# 147, 148, 153 and 154. Working crossed by the single fracture, recorded at the end of the last century. On the basis of data of vibroacoustic diagnostics on 
the site the three-stage signaling device with a step of operation of steps of $2 \mathrm{~mm}$ was established.

Systematic overseeing by a condition of a signaling device showed the progressing lowering of the muck block in a roof from the pillars \# 147 - 154. The first stage of a signaling device worked in 2012, and the second in 2018. Considerably the area of stratification of a protective pack increased in a chamber of roof. The condition of a roof on this site of the main transport gallery of the gypsum mine in December, 2018 is illustrated by Figure 10 .

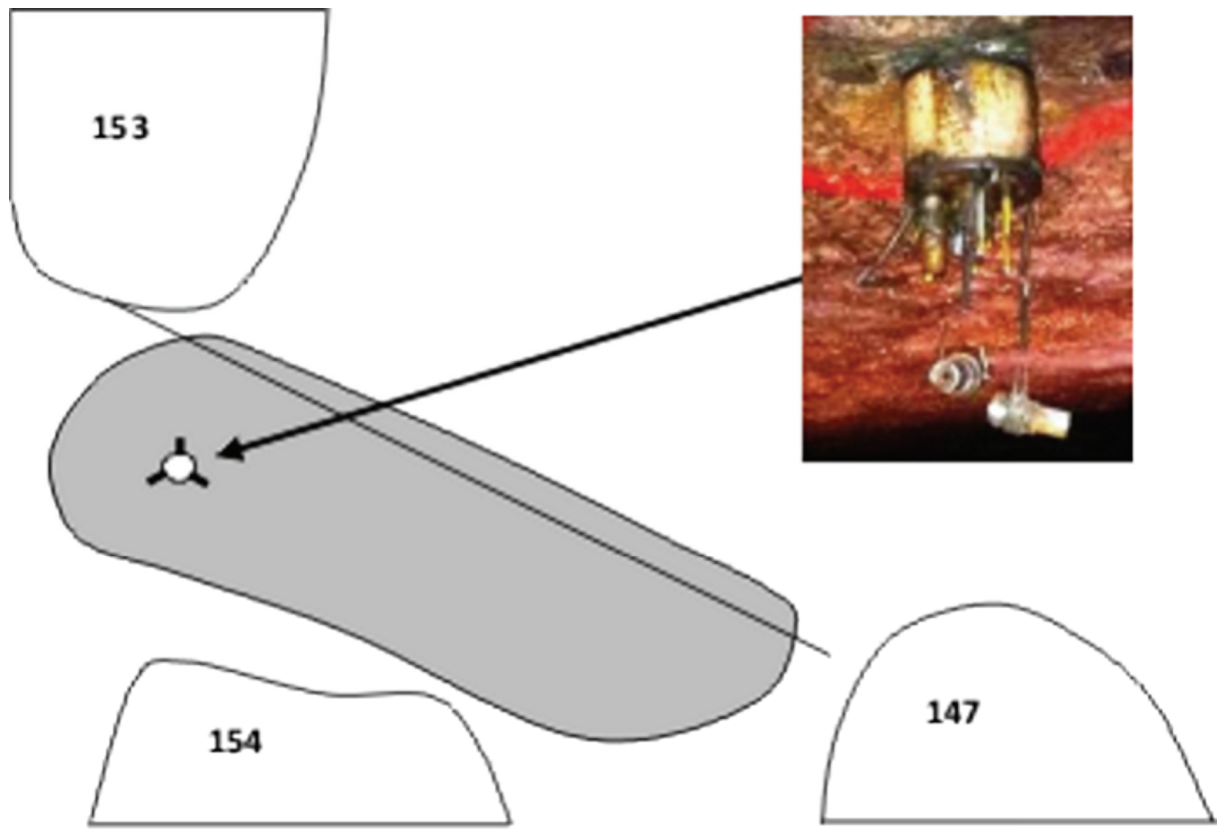

Fig. 10. The site of a roof vertical displacement on the main transport gallery between pillars \# 153, 154,147 with a view of the triggered deformations signaling device.

On sites of the mine take with geological faults of rock mass deformation processes happen more intensively. Local faults are grouped in zones. By results of monitoring 22 dangerous zones are allocated. Conducting mining operations on some sites is carried out on the special project. Some characteristics of three large dangerous zones are presented in Table 6.

Table 6. Selection of dangerous zones by results of geomechanical monitoring.

\begin{tabular}{|c|c|c|l|}
\hline $\begin{array}{c}\text { Conditional } \\
\text { number }\end{array}$ & $\begin{array}{c}\text { Area, } \\
\mathrm{m}^{2}\end{array}$ & $\begin{array}{c}\text { Disposition of } \\
\text { a zone (stall) }\end{array}$ & \multicolumn{1}{|c|}{ Typical forms of a faults of the massif } \\
\hline 6 & 52100 & IV, V, VI & Karst, partially humid \\
\hline 21 & 15200 & VII & Karst, small-amplitude tectonics \\
\hline 22 & 17800 & VII & Karst, with inrush of rocks in the chamber \\
\hline
\end{tabular}

\section{Conclusions}

Need of the organization of complex monitoring of the weakest link of an underground geomechanical system - a roof of workings is proved. Three levels of monitoring for diagnostics problem solving of varying complexity are recommended. The efficiency of complex use of visual observations, tool measurements and vibroacoustic diagnostics is 
established. On the example of the gypsum mine in Bakhmut stages of development of deformation processes in a roof of heave-gage workings are shown. Acceleration of their development in zones of geological flaws is established. Experience of the organization of monitoring can be recommended also for mines on extraction of anhydrite, a saw stone and marble.

\section{References}

1. Amelin, V.A., Vasilyev, B.V., Kucherenko, S.A., Amelina, L.V. (2010). The technological control of ceilings chambers on gypsum mines. Geotekhnicheskaya Mekhanika [Geo-Technical Mechanics], (91), 122-127

2. Cheskidov, V.V., Kurenkov, D.S., Manevich, A.I. (2017). The modern methods and means of operating control in mines for support ecological and industrial safety. Gornyu informatsionno-analiticheskiy byulleten [Mining informational and analytical bulletin], (6), 188-199

3. Yeremenko, V.A., Yesina, Ye.N., Semenyakin, Ye.N. (2015). Technology of monitoring of an intense strained state of the developed massif of rocks. Gornyu zhurnal, (8), 42-47

4. Baryshnikov, V.D., Baryshnikov, D.V., Gakhova L.N., Kachalsky, V.G. (2014). Practical experience of geomechanical monitoring in underground mineral mining. Journal of Mining Science, (5), 61-73

5. Lashenko, V.I. (2016). Development of geomechanical monitoring of properties and a condition of the massif of rocks by underground mining of fields of the complex structure. Marksheyderskiy vestnik, (1), 35-43

6. Abramovich, A.S., Pudov, Ye.Yu., Kusin, Ye.G. (2017). Prerequisites of creation of a system of the automated monitoring and accounting of shifts of a roof of underground developments for the purpose of increase in safety of maintaining horns of works. Vestnik KGTU, (5), 85-90

7. P. Strzalkowski, K. Tomiczek, Proposal of a methodology assessing the risk of sink holes formation in mining areas, International Journal of Mining Sciences and Technology, 1, 85-89 (2015)

8. NPAOP 0.00-1.77-16. (2017). Pravyla bezpeky pid chas rozrobky rodovychch rudnykh ta nerudnykh korysnych kopalyn pidzemnym sposobom. Kyiv: MSP

9. Skipochka, S.I., Sergienko, V.N. (2014). Equipment SHVK-1 for the vibroacoustic control of a condition of a rock mass. Geotekhnicheskaya Mekhanika [Geo-Technical Mechanics], (119), 79-86

10. Antsyuferov, A.V. (2010). Geomekhanichnyu monitoryng pidzemnykh geotekhnichnykh system. Donetsk: Noulidg

11. Bulat, A.F. (2009). Metodicheskie rekomendatsii po geofizicheskomu kontrolyu $i$ diagnostike geomekhanicheskogo sostoyaniya podzemnykh geotekhnicheskikh sistem ugolnykh shakht. Dnipro: IGTM NAS of Ukraine

12. Tokin, A.A. (2013). Monitoring of deformations of underground excavations by means of the laser scanning systems. Interekspo Geo-Sibir, (1), 120-123 